\title{
Reviews
}

\section{IDM Data Council open data discussion}

\section{Does open data threaten commercial data?}

\section{Intermediaries \\ managing open data}

Journal of Direct, Data and Digital Marketing Practice (2013) 15, 166-169. doi:10.1057/dddmp.2013.56

In October, the IDM held its first-ever joint event with the Open Data Institute (ODI) (see review on pages 176-179). Ahead of the evening, the IDM Data Council discussed the implications of the open-data movement for the conventional data industry during a meeting held in September. Among the issues considered were the extent to which commercial data owners are considering open data as part of their own strategic development and whether the arrival of a new set of data providers will be a good thing for the industry, by broadening the supporter base, or a bad thing because it could erode the revenue sources of existing suppliers.

Marie Myles, director of consulting at Experian Marketing Services, said: 'We are looking at open data and the possibility of acting as an intermediary. The whole area of consumer access to data is something we are evaluating'. One of the unanswered questions about open data is how consumers will make use of the transactional data that they have a right to view. A number of businesses are looking to act as trusted agents on their behalf, taking this newly accessible data and identifying opportunities based on it, such as lower-energy tariffs.

'Through the open data space, companies will have to provide their data into intermediaries and that will give individuals more control over how their data is used and stored', pointed out Shaun Pitman, head of data strategy at British Gas Business. This will bring the world of open data and the new Personal Data Store model into alignment. 'That will give them more power than they have in the conventional data space. It is democratising data as people become more concerned about who is handling their data and how it is released. The open data space may be the vehicle through which start-ups come through and say, "we'll protect you and help you decide when to release it" '.

This is putting energy companies themselves into a curious position as both providers of the data that enables switching and also providers of the lower tariffs that tempt consumers to switch. 'Consumers are hearing the Government say they want them to have choice, especially in the energy market. On the other hand, there are rules about who can be marketed to. There is a tension there', pointed out Martin Aylward, head of customer marketing at EDF Energy. 'Within the business, we have to look at whether the customer is on the right deal for them and the Government is very keen to encourage switching. So it will be interesting to see the role of open data aggregators'. 
Integrating data sources is nothing new

B2B less prone to open data initiatives

\section{Publishers of open data, not just consumers}

\section{Can open data be used for DM?}

Bringing together data from multiple sources is nothing new in the data industry. In this respect, open data could just form another set, which is added into databases that help marketers to understand their prospects and customers. For some, it may create whole new insights that help to trigger marketing campaigns or define propositions.

'We have had a lot of queries from our clients about this', noted Anne Stagg, commercial director at Communisis Data Intelligence. 'We don't own data but aggregate from multiple sources and clients are asking us about using new, open sources. We're seeing increasing curiosity from clients about how we are evaluating those. Clients are also concerned about what open data means for them - will consumers be less willing to be marketed to? The key is to provide relevant, valuable content to consumers'.

One area of the data industry that may stay unaffected by open data could be business-to-business (B2B). Current legislation around open data is focused on four key consumer products, although there may be possibilities to use data found in open Government data sets where the principle was first pioneered. Operators in this sector believe that opening up new data will force the industry to get better at generating insight, rather than just focusing on the source.

'If there is a threat from open or free data sources, then I would see the B2B data world evolving towards that added-value model and leaving the data as a commodity. One of the dangers of this is what the open data will actually be. Some suppliers will have to up their game - and that's a good thing', said Robbie Burgess, database marketing director at Reed Business Information. 'We play in the B2B space and the data is very niche - we are famously the publisher of Poultry World! A lot of business data comes from the publishing background - differentiating it is important. Just supplying the data is not enough, you have to support the client using it and help them spot the opportunities'.

One of the challenges that the ODI faces is in getting more companies to become publishers of data, rather than just consumers. To do that, it will need to convince them of the benefits and also show them what best practice around open data looks like, especially when it comes to deciding how to anonymize it. In discussing this point, a number of members of the Council pointed out that the need to prevent data from being capable of identifying individuals also limits its value to marketers.

Ross Simson, BBC TVL insight, analytics and service development director at The Capita Group, said: 'We all want to consume data, to get data that informs us, is personal and relevant — and increasingly which has a location element as well - both as consumers and as businesses. A lot of the open data sets I have looked at are aggregated at too high a level. It might be useful for certain applications, but what will be critical is what can be shared'.

This was backed up by Tim Drye, managing director of DataTalk. 'Most open data excludes using it for direct marketing. What you can do, once you've aggregated it, is to build models and define strategy. One of the things that fascinates me is the NHS prescription data on every GP practice. You can look at the response to things like infections as they 


\section{Risks of data sources which are not stable}

\section{PAF as an open data source}

spread. But you can you use that to execute anything'? One of the first start-ups supported by the ODI did use this prescribing data to map where doctors were over-subscribing branded statins. If these practices could be persuaded to use identical, generic versions, it would save the National Health Service hundreds of millions of pounds each year.

An example of how open data that is not personal could be used in marketing was provided by Council chair James Morgan, head of information strategy and management at Telefónica UK. In France, data on the location of the snow line in mountainous areas has been used to map tyre dealerships and target the sale of snow tyres. 'That is an interesting case that is not personal data', he said. His own business has been looking at using open data web classification.

For Morgan, there is an issue of how to operationalize open data: 'How many companies will be willing to source data from an open source, integrate it and trust the provenance? Companies that can't afford large data management or analytics teams will rely on agencies to build that for them so they don't have to worry about it'. There was general agreement that in the early phase of development, open data will be trialled and derisked either by start-ups or by agencies working on behalf of larger clients.

Drye argued that, in this respect, open data will mirror a shift in the software sector. 'The open source community is an excellent place to run tests and prototypes and get new ideas. However, when you move into a commercial environment, you get a lot of costs in supporting that. Open source is good for trials, but once it becomes commercial you need somebody to take on the risk of turning it into something stable', he said. Concerns were also voiced about whether open data will be reliable why take the risk of developing a new business model on the assumption that certain information will be available if the data format or content might change within a year? Comments showed that this has already happened with early open data sources, such as the Land Registry where field definitions have been altered and required effort to consolidate.

Perhaps the biggest argument about the open versus commercial model for any data set was recently staged around Postal Address File (PAF). As one of the most widely used data sources - and a significant cost to direct marketers - a lot of pressure was placed on the Government and Royal Mail to transform it into an open data source. 'It has been clear that not many people in the Cabinet Office understand the issues', said Drye. 'They have forced Royal Mail to come out with a new licence model that runs against what it used to be. I am very keen for it not to be open because of the quality issue. Once you take away payment by users, the quality deteriorates because there is no benefit in running it. Royal Mail could just trash the file'. Some members suggested that quality was already suffering, despite the licence fees charged for access to PAF, however.

The issue of revenue streams was returned to several times during the discussion, with several Council members pointing out that the start-ups supported by the ODI do not currently have to worry about operating in a fully commercial fashion. Morgan argued that it may be too early to place these businesses under the pressure to deliver financial returns. 


\section{Prototyping and innovating}

'Some of the power is in the "what-if ?" prototyping and understanding correlations between data and assets. It is not about creating a commercial product in the first instance, but understanding the relationships and whether there could be a value in the information, then looking at how to turn it into an industrial grade product. There is an opportunity to look at areas on which we haven't had information before and whether there is any benefit', he said.

Both the ODI and IDM are innovating in their own right and mutually, through the new Open Data for Marketers training programme, which has been jointly developed and will run in early 2014. The course will run first at the ODI in January and then again in March at the IDM and is aimed at both client side and agency practitioners, entrepreneurs and start-ups, policymakers and strategists. It will educate participants about the differences between open, closed and personal data, the opportunities and benefits of open data, together with the potential Return on Investment. Issues around licensing and intellectual property will be addressed, plus how to find, assess and use open data sets. Both the ODI and IDM will contribute case studies and best practice examples to make this the most valuable course on the subject for marketing professionals.

If such projects bring together the commercial muscle of existing data users and service providers with the innovative drive of the start-ups, it could help to transform the data industry.

David Reed FIDM

\section{DataIQ Future Summit 2013 - Conference review}

Trends in technology, business and society

Missing meals to buy
phone credits
Journal of Direct, Data and Digital Marketing Practice (2013) 15, 169-175. doi:10.1057/dddmp.2013.51

DataIQ's annual Future Summit has become a fixture in the conference calendar since it launched 3 years ago. Unlike other events that focus narrowly on marketing or business strategy, what differentiates the summit, which ran on 15 October 2013, is the way it looks at a range of trends across technology, business and society and seeks to identify which will have the biggest impact.

Author Tom Chatfield opened the event by pointing out that the most important technology in history has been writing since it has allowed ideas to propagate. 'Writing is data that endures after death. In ancient Egypt, there was a death penalty for trying to write without being a licenced scribe. That meant a few were being employed on the behalf of the many, so we have no view of people beyond the official record', he said.

That situation endured until as recently as 75 years ago when mass literacy led to over half of the world's population being able to write and therefore to record their personal data. The last decade has seen a yet 